\title{
Una cartografía para los once condados de la diócesis de Lugo: hacia una nueva aproximación al Parrochiale Suevum ${ }^{1}$
}

\section{A cartography for the eleven counties of the dioceses of Lugo: towards a new approach to the Parrochiale Suevum}

\author{
Mariña BERMúdez Beloso \\ Universidade de Santiago de Compostela \\ marina.bermudez@usc.es \\ Luis Manuel IBÁÑ̃̃ BeLtrÁN \\ Universidade de Santiago de Compostela \\ luismanuel.ibanez@usc.es
}

Fecha de recepción: 15-04-2019

Fecha de aceptación: 16-05-2019

\section{RESUMEN}

Se considera que el texto conocido como Parrochiale Suevum fue originariamente escrito en el siglo VI, pero la relevancia de su contenido lo convirtió en objeto de varias copias interpoladas en las centurias sucesivas. En todas las versiones alteradas del documento que se han conservado el obispado de Lugo está organizado en once comitatus. En este artículo analizaremos un documento que presenta una detallada descripción de estos condados, en un grado de precisión que permite la reconstrucción cartográfica de cada uno de ellos. Aunque la fecha proporcionada en el texto es el 572, la evidencia histórica sitúa su redacción a finales del siglo XI, dentro de un contexto más amplio y agitado en las diócesis ibéricas occidentales. Este artículo propone un análisis detallado del documento que describe los comitatus, combinando las herramientas proporcionadas por las Humanidades Digitales, los SIG en particular, con una metodología histórica más tradicional. EI mapa resultante proporciona el punto de partida para una mejor comprensión de las ambiciones del obispo de Lugo sobre el territorio y del contexto político y religioso del siglo XI, así como del propio Parrochiale Suevum.

Palabras clave: Parrochiale Suevum, comitatus, diócesis de Lugo Topónimos: Lugo, Galicia

Periodo: siglo VI, siglo XI

1 Este trabajo se incluye en el marco del proyecto de investigación "El Papado y sus relaciones con la sociedad y los reinos de la Península Ibérica (ss. VIII-XIII): protagonistas, tipos de contactos, problemas y consecuencias integradoras (I)"-RETOS-2015-PN144, que se lleva a cabo en el Departamento de Historia, Área de Medieval, de la Universidade de Santiago de Compostela, bajo la dirección del Dr. Fernando López Alsina, y en el grupo de investigación GI-1548 Historia Medieval: Sociedad y Territorio de la misma universidad. 


\section{ABSTRACT}

The text known as Parrochiale Suevum is considered to have been originally written in the $6^{\text {th }}$ century, but the relevance of its content made it the object of several interpolated copies in the following centuries. In all the altered versions of the document that have been preserved, the bishopric of Lugo is organised into eleven comitatus. In this article we analyse a document that presents a detailed description of these counties, with a degree of precision that permits the cartographical reconstruction of each of these. Although the date provided in the text is 572 , historical evidence locates its composition in the late $11^{\text {th }}$ century, within a wider and more turbulent context in the dioceses of western Iberia. This article proposes a careful analysis of the document that describes the comitatus, combining the tools provided by Digital Humanities, GIS in particular, with a more traditional historical methodology. The resulting map provides the starting point for a better comprehension of the ambitions of the Bishop of Lugo's territorial ambitions and of the political and religious context of the $11^{\text {th }}$ century, as well as of the Parrochiale Suevum itself.

Key words: Parrochiale Suevum, comitatus, diocese of Lugo

Place names: Lugo, Galicia

Period: $6^{\text {th }}$ century, $11^{\text {th }}$ century

\section{INTRODUCCIÓN}

El Parrochiale Suevum es una relación de las parroquias correspondientes a cada una de las trece diócesis existentes en el reino suevo, supuestamente compuesta a raíz de un concilio celebrado en Lugo en el siglo $\mathrm{VI}^{2}$. Las notables interpolaciones de las cuatro versiones más valiosas, conservadas en Lugo, Braga y Santiago y conocidas como A, B y C, y $\mathrm{D}^{3}$, provocaron controversia en torno a su veracidad y utilidad, extremo en el que terciaría la publicación de P. David, quien lo consideró digno de fe y de utilidad en lo que al listado de

2 Son varias las ediciones que han sido publicadas de las distintas transmisiones de este texto, entre otras: P. David, Études historiques sur la Galice et le Portugal du Vle au XIle siècle, Lisboa, Institut Français au Portugal, 1947, pp. 30-44; Itineraria et alia geographica, Turnholt, Brepols, 1965, pp. 413-420; F. López Alsina, "El Parrochiale Suevum y su presencia en las cartas pontificias del siglo XII", en K. Herbers, F. Engel y F. López Alsina (eds.), Das begrenzte Papsttum: Spielräume päpstlichen Handelns, Legaten, delegierte Richter, Grenzen, Berlín, De Gruyter, 2013, pp. 128-131.

El concilio lucense se habría celebrado después del II Concilio de Braga, probablemente en algún momento entre el 576 y el 582, reflejándose en este documento buena parte de la organización eclesiástica de Galicia y el norte de Portugal en este momento, casi simultáneo a la integración del reino suevo en el godo de Toledo. En J. López Quiroga, "El I y II Concilios de Braga y el 'parroquial suevo': Élites eclesiásticas y control del territorio en la Gallaecia del siglo VI", en J. López Quiroga (coord.), In tempore sueborum: el tiempo de los suevos en la Gallaecia (411-585), el primer reino medieval de occidente, Ourense, Deputación de Ourense, 2018, pp. 139-144.

El preámbulo recoge igualmente la conversión de Lugo en sede metropolitana, extremo que ha suscitado visiones enfrentadas en torno a su veracidad entre los estudiosos, y que se inserta en una historia compleja de los primeros siglos de la sede lucense, al menos entre el I Concilio de Toledo y las noticias que recoge Hidacio en torno a la elección de los obispos Pastor y Siagrio, y los capitula Martini del 572. El rango metropolitano queda atestiguado en los concilios II y III de Braga. Véase mejor información sobre estos momentos de la iglesia de Lugo en M. C. Díaz y Díaz, "Orígenes cristianos en Lugo", en Actas del Coloquio Internacional sobre el Bimilenario de Lugo, Lugo, Patronato del Bimilenario, 1977; D. Mansilla Reoyo, Geografía Eclesiástica de España. Estudio histórico-geográfico de las diócesis, Roma, Iglesia Nacional Española, 1994, vol. I, pp. 149153; y J. M. Novo Güisán, "Lugo en los tiempos oscuros: las menciones literarias de la ciudad entre los siglos V y X", en Boletín do Museo Provincial de Lugo, t. 8, vol. 2 (1997-1998), pp. 177-194.

3 J. C. Sánchez Pardo, "Organización eclesiástica y social en la Galicia tardoantigua. Una perspectiva geográfico-arqueológica del parroquial suevo", Hispania Sacra, vol. LXVI, 134 (2014), pp. 441-442. 
la mayor parte de parroquias se refiere ${ }^{4}$. Todas ellas contienen dos ideas introducidas por Lugo en la Plena Edad Media: la distribución de esta diócesis en XI comitatus y el carácter personal de la diócesis de Mondoñedo, cuyas eventuales demandas territoriales sitúa en Asturias ${ }^{5}$.

Recoge, en cualquier caso, buena parte de las protoparroquias noroccidentales, iglesias al frente de un distrito rural a las que, al estilo de las pieve italianas ${ }^{6}$, el obispo transfiere la administración de varios sacramentos otrora exclusivos de la sede episcopal, particularmente el bautismo ${ }^{7}$. Estos la singularizan y jerarquizan frente a los templos de su distrito, que deberán celebrar una serie de festividades anuales en su iglesia bautismal ${ }^{8}$.

El contexto de esas interpolaciones es, sin duda, el siglo XI, cuando el frente galaicoportugués solo conoce cuatro sedes episcopales: Iria, Mondoñedo, Lugo y Oporto, y el espacio intermedio entre unas y otra se reparte entre las sedes gallegas y Astorga, mientras Oviedo y León tienen a cambio importantes territorios del entorno lucense. Tras la conquista de Coímbra (1064) una reorganización se hace perentoria y la iglesia leonesa se dispone a acometer la restauración de las sedes de Tui, Ourense y Braga. La vuelta de estas dos últimas resulta particularmente lesiva para los dominios lucenses, con lo que el obispo Amor se dirige a Roma con toda una batería de documentos falsos e interpolados que reclaman lo que supuestamente en el pasado había sido suyo y a la sazón se encontraba en manos de Oviedo, León y Mondoñedo. Entre toda esa documentación estaba el propio Parrochiale, un segundo texto en el que desarrolla las dimensiones de cada condado el protagonista de este artículo-, y un falso atribuido a Alfonso II. En este último, Lugo muy hábilmente introduce la idea de que estos espacios deberían volver a su dominio una vez restaurada Braga. Con ello aspiraba también a conseguir un territorio diocesano homogéneo y coherente donde ejercer la jurisdicción episcopal de manera efectiva, en línea con lo suscrito en el Concilio de Coyanza ${ }^{9}$.

Con esta acción Lugo abre las hostilidades con Ourense y Astorga, limitadas en sus aspiraciones, pero sobre todo con Oviedo y Mondoñedo, muy dañadas en sus intereses. Frente a ello, se granjea un aliado en Iria-Santiago. Las reacciones no se harán esperar y en mayor o menor medida todas las sedes afectadas se lanzarán a la carrera falsificadora, aunque ninguna con la prolijidad de Oviedo y su obispo Pelayo, dando origen al denominado Corpus pelagiano y a un conjunto de pleitos que no terminarán hasta $1154^{10}$. Ourense iniciará a su vez otro frente incluyendo Lemos y la Limia entre el listado de territorios que le consignaba el Parrochiale Suevum ${ }^{11}$. Del mismo modo, un largo conflicto se establecerá

4 P. David, Études historiques..., p. 82. P. de la C. Díaz Martínez, "El Parrochiale Suevum: organización eclesiástica, poder político y poblamiento en la Gallaecia tardoantigua", en J. Mangas, y J. Alvar (eds.), Homenaje a José $M^{a}$ Blázquez. Vol. VI Antigüedad: religiones y sociedades, Madrid, Ediciones Clásicas, 1998, pp. 35-36.

5 F. López Alsina, “El Parrochiale Suevum...", pp. 111-113.

6 A. Castagnetti, La pieve rurale nell'Italia padana. Territorio, organizzazione patrimoniale e vicende della pieve veronese di San Pietro di "Tillida" dall'alto medioveo al secolo XIII, Roma, Herder, 1976, pp. 4-8.

7 F. López Alsina, "Da protoparroquia ou parroquia antiga altomedieval á parroquia clásica en Galicia”, en F. García Pazos (coord.), A parroquia en Galicia: presente, pasado e futuro, Santiago de Compostela, Xunta de Galicia, 2009, pp. 58-63.

8 M. Aubrun, La paroisse en France: des origines au XVe siècle, París, Picard, 2008, pp. 14-15.

9 F. López Alsina, "El Parrochiale Suevum...", pp. 105-118.

10 1154. Alfonso VII da a la iglesia de Lugo los límites pretendidos y compensa a Oviedo con bienes de la corona. En J. L. López Sangil y M. Vidán Torreira, "Tumbo viejo de Lugo (transcripción completa)", Estudios Mindonienses, 27 (2011), doc. 29, pp. 93-94.

11 [900]. Alfonso II restaura el patrimonio de la diócesis ourensana. En M. B. Vaquero Díaz y F. J. Pérez 
con León, que al igual que Oviedo controlaba algunos territorios del entorno lucense ${ }^{12}$. Mondoñedo, por su parte, buscará también el amparo papal frente al desmedido ataque de su vecina meridional ${ }^{13}$. Astorga, sin embargo, focalizó sus enfrentamientos en Ourense y Braga $^{14}$.

En este mismo contexto tiene lugar una disputa entre Mondoñedo y Compostela por el control de los arciprestazgos de Labacengos, Trasancos, Bezoucos, Seaia y Arros de la que dan cuenta la Historia Compostellana ${ }^{15}$ y algunos documentos conservados en los fondos de la catedral mindoniense ${ }^{16}$. Dichas entidades ocupaban el espacio noroccidental de la actual Galicia, en la parte norte de la costa atlántica. Según narra el texto compostelano, en el año 1102 el obispo Diego Gelmírez reclama a su homólogo de Mondoñedo, Gonzalo Froilaz, los arciprestazgos de Bisancos, Trasancos y Salagia ${ }^{17}$. En la primera resolución del conflicto, que no resultó ser la definitiva, la lista de entidades varía ya que desaparece Salagia y se incorporan Lauacencos y Arros $^{18}$. Una concordia del año 1122 pondrá fin a la controversia; en ella se determina que Salagia y Bezoucos permanezcan en manos de Compostela y Trasancos, Lauacencos y Arros en las mindonienses ${ }^{19}$. Este episodio constituye una muestra más de las ambiciones territoriales que dominan las relaciones entre obispados a finales del siglo XI e inicios del XII, y cómo Mondoñedo y su territorio diocesano fueron codiciados por las sedes vecinas.

\section{HIPÓTESIS Y METODOLOGÍA}

El texto objeto de análisis en este estudio, en adelante Deo omnipotenti siguiendo su incipit, está directamente vinculado con el mencionado Parrochiale, Tempore suevorum en lo sucesivo siguiendo el mismo principio. Se cree que fue concebido como una ampliación de su contenido para el caso concreto de la diócesis de Lugo, autora y principal interesada en las interpolaciones obradas sobre el texto en los siglos XI y XII.

La hipótesis de partida propone que la reconstrucción de los límites de los condados mediante la identificación de las referencias geográficas mencionadas en el documento proporciona una imagen fiable del espacio diocesano reivindicado por la iglesia de Lugo

Rodríguez, Colección documental del Archivo de la Catedral de Ourense, Tomo I (888-1230), León, Centro de Estudios e Investigación "San Isidoro", Caja España de Inversiones, Archivo Histórico Diocesano, 2010, doc. 2, pp. 50-53.

12 S. Domínguez Sánchez, "El papel de los legados y de los jueces pontificios en la lucha de los Obispados de León y Lugo por Triacastela", en Das begrenzte Papsttum..., pp. 237-248.

13 F. López Alsina, "El Parrochiale Suevum...", pp. 120-126.

14 C. Álvarez y G. Cavero Domínguez, "La diócesis de Astorga, entre el reino de León y la sede de Braga", en L. Adão da Fonseca, L. C. Amaral y M. F. Ferreira Santos (coords.), Os reinos Ibéricos na Idade Média: livro de Homenagem ao Professor Doutor Humberto Carlos Baquero Moreno, Porto, Livraria Civilização, 2003, vol. I, pp. 337-339.

15 Concretamente en los cap. XXXIV, XXXV y XXXVI del lib. I y en el cap. LVI del lib. II. Historia Compostellana, cvra et stvdio Emma Falque Rey, Turnholti, Brepols, 1988, pp. 64-76, pp. 328-333. Para la traducción: Historia Compostelana. Introducción, traducción, notas e índices de Emma Falque, Madrid, Akal, 1994, pp. 133-144, pp. 403-407.

16 La concordia final entre los obispos Gelmírez y Munio Afonso aparece recogida en la edición de los fondos de la catedral de Mondoñedo, además de en la propia Historia Compostellana. E. Cal Pardo, Colección diplomática medieval do Arquivo da Catedral de Mondoñedo, Santiago de Compostela, Consello da Cultura Galega, 1999, doc. 10, pp. 23-24.

17 E. Falque Rey, Historia Compostellana, lib. I, cap. XXXIV, pp. 64-68.

18 Ibídem, lib. I, cap. XXXV, pp. 69-74.

19 Ibídem, lib. II, cap. LVI, pp. 328-333; E. Cal Pardo, Colección diplomática medieval..., doc. 10, pp. $23-24$. 
frente a sus vecinos. Al mismo tiempo, su análisis detallado contribuirá a una mejor comprensión de Tempore suevorum y de las intenciones que se podrían ocultar detrás de estas interpolaciones relacionadas con Lugo, permitiendo una comprensión del mismo que ha sido ignorada hasta ahora.

Los Sistemas de Información Geográfica o SIG (más conocidos como GIS por sus siglas en inglés) constituyen una herramienta de gran valor para abordar el estudio de fuentes como la indicada, en combinación con instrumentos de búsqueda toponímica ${ }^{20}$ y con CODOLGA, corpus documental utilizado durante el proceso de identificación de determinados nombres de lugar ${ }^{21}$. A través del programa QGis se señalarán en el mapa mediante puntos las localizaciones actuales propuestas para los distintos topónimos. Además se tendrá en cuenta la orografía y la hidrografía para delimitar perfiles, siguiendo el papel otorgado a ríos, montes y valles como elementos delimitadores de entidades territoriales ${ }^{22}$. Una vez perfilados los límites, sobre la base de la red parroquial actual (asumiendo las reservas que esto implica), se procederá a unir los polígonos ${ }^{23}$, con la intención de señalar el término de cada comitatus. El objetivo final no es realizar una reconstrucción exacta y precisa de las dimensiones sino visualizar el espacio diocesano aproximado que Lugo reivindica para sí en el siglo XI y con el que se explica la adyacencia que se atribuye en Tempore suevorum.

\section{DEO OMNIPOTENTI: ANÁLISIS Y PROPUESTA CARTOGRÁFICA}

El documento presenta una estructura en tres partes, comenzando con la confirmación del rey Teodomiro de los límites acordados en el II Concilio de Braga para la diócesis lucense, por lo tanto en el año 572. El monarca se presenta como "Theodemirus Rex cognomento etiam Mirus -Galletie totius Prouintie Rex- (...)"24. A la iglesia de Lugo se le habían concedido once condados junto con Seuios ${ }^{25}$, Cauarcos et Carioga.

A continuación se procede a la descripción de los límites de cada uno de los once condados con distinto grado de detalle. Inicia el recorrido en el situado al este del centro diocesano (Flamosis) y prosigue en el sentido de las agujas del reloj, por Superata hasta llegar a Montenegrinus. En la tercera parte toma la palabra el obispo Nitigio y se declara la voluntad de acabar con las disputas entre la iglesia lucense y otras. Finalmente se data el texto, que concluye con las subscripciones de los demás obispos presentes.

Por lo que respecta a la descripción, el reparto de las 159 referencias geográficas identificadas es notablemente desigual según el condado, tal y como se resume en la tabla 1.

20 Nomenclátor de Galicia, Xunta de Galicia, https://www.xunta.gal/nomenclator (Consulta: 14-11-2018).

21 Corpus Documentale Latinum Gallaeciae (CODOLGA), Santiago de Compostela, Centro Ramón Piñeiro para a Investigación en Humanidades, 14 (2017), http://cirp.gal/codolga/ (Consulta: 07-05-2019).

22 E. Portela Silva, La región del Obispado de Tuy en los siglos XII a XV, Santiago de Compostela, El Eco Franciscano, 1976, p. 258. F. López Alsina, La ciudad de Santiago de Compostela en la Alta Edad Media, Santiago de Compostela, Ayuntamiento de Santiago de Compostela, 1988, pp. 220-221.

23 La base es una capa vectorial tipo polígono, en la que cada polígono representa una parroquia según sus dimensiones actuales.

24 J. L. López Sangil y M. Vidán Torreira, “Tumbo viejo...”, doc. 6, pp. 42-46.

25 Los editores transcriben "Lemos", pero el manuscrito indica Seuios. Archivo Histórico Nacional, CODICES, L.1043, f. 05v-06v, a través de http://pares.mcu.es/ (Consulta: 15-11-2018). 
Tabla 1. Número de referencias y extensión de cada comitatus ${ }^{26}$

\begin{tabular}{|c|c|c|}
\hline Comitatus & $\begin{array}{c}\text { Número de } \\
\text { referencias }\end{array}$ & Extensión \\
\hline Flamosis & 17 & $562,75 \mathrm{~km}^{2}$ \\
\hline Superata & 19 & $928,16 \mathrm{~km}^{2}$ \\
\hline Nauiensis & 13 & $1.016,52 \mathrm{~km}^{2}$ \\
\hline Sarriensis & 17 & $1.438,79 \mathrm{~km}^{2}$ \\
\hline Paramensis & 20 & $1.168,24 \mathrm{~km}^{2}$ \\
\hline Palarensis & 14 & $693,63 \mathrm{~km}^{2}$ \\
\hline Decensis & 9 & $956 \mathrm{~km}^{2}$ \\
\hline Durriensis & 18 & $678,2 \mathrm{~km}^{2}$ \\
\hline Uliensis & 6 & $118,11 \mathrm{~km}^{2}$ \\
\hline Nallarensis & 14 & $990,81 \mathrm{~km}^{2}$ \\
\hline Montenegrinus & 12 & $3.131,9 \mathrm{~km}^{2}$ \\
\hline Total & 159 & $11.683,11 \mathrm{~km}^{2}$ \\
\hline
\end{tabular}

Fuente: elaboración propia a partir de los datos extraídos del documento analizado

El documento concreta el método general que se sigue en la delimitación, la indicación de ríos, montes y antiguos castros: riuulorum, montium y antiquorum castrorum; fluminum y castrorum aparecen de nuevo en la parte final ${ }^{27}$. La tabla 2 recoge los diferentes tipos de referencias geográficas, con las tres mencionadas expresamente entre las cinco más frecuentes.

26 J. L. López Sangil y M. Vidán Torreira, "Tumbo viejo...", doc. 6, pp. 42-46. Los datos de extensión fueron calculados a través de la herramienta "Calculadora de campos" del programa QGis, en función de los perímetros delimitados para cada entidad a partir de la descripción que de ellas se hace en el texto.

27 Ibídem, doc. 6, pp. 42-46. 
Tabla 2. Tipos de referencias geográficas ${ }^{28}$

\begin{tabular}{|c|c|c|}
\hline Orónimo & 40 & $25,16 \%$ \\
\hline Topónimo & 31 & $19,5 \%$ \\
\hline Hidrónimo & 29 & $18,24 \%$ \\
\hline Peña/Piedra/Anta & 13 & $8,18 \%$ \\
\hline Castro & 12 & $7,55 \%$ \\
\hline Fuente & 5 & $3,14 \%$ \\
\hline Villa/Villare & 5 & $3,14 \%$ \\
\hline Campo & 4 & $2,51 \%$ \\
\hline Puente & 4 & $2,51 \%$ \\
\hline No definido/ & 4 & $2,51 \%$ \\
\hline dudoso & 3 & $1,89 \%$ \\
\hline Puerto & 2 & $1,25 \%$ \\
\hline Túmulo (mamola) & 2 & $1,25 \%$ \\
\hline Portella & 2 & $1,25 \%$ \\
\hline Entidad territorial & 1 & $0,63 \%$ \\
\hline Locus & 159 & $0,63 \%$ \\
\hline Castillo & 1 & $0,63 \%$ \\
\hline Cruces & 15 & \\
\hline Total & 1 & \\
\hline
\end{tabular}

Fuente: elaboración propia a partir de los datos extraídos del documento analizado

Estas consideraciones generales sobre el documento constituyen el punto de partida para el análisis detallado de su contenido, con el destacado peso de las presencias y ausencias como factores de importancia equiparable para comprender las motivaciones que llevaron a su redacción y lo que con él se pretendía conseguir. Partiendo de las descripciones de cada uno de los comitatus se procedió a elaborar el siguiente mapa. 
Figura 1. Reconstrucción de los comitatus de Lugo

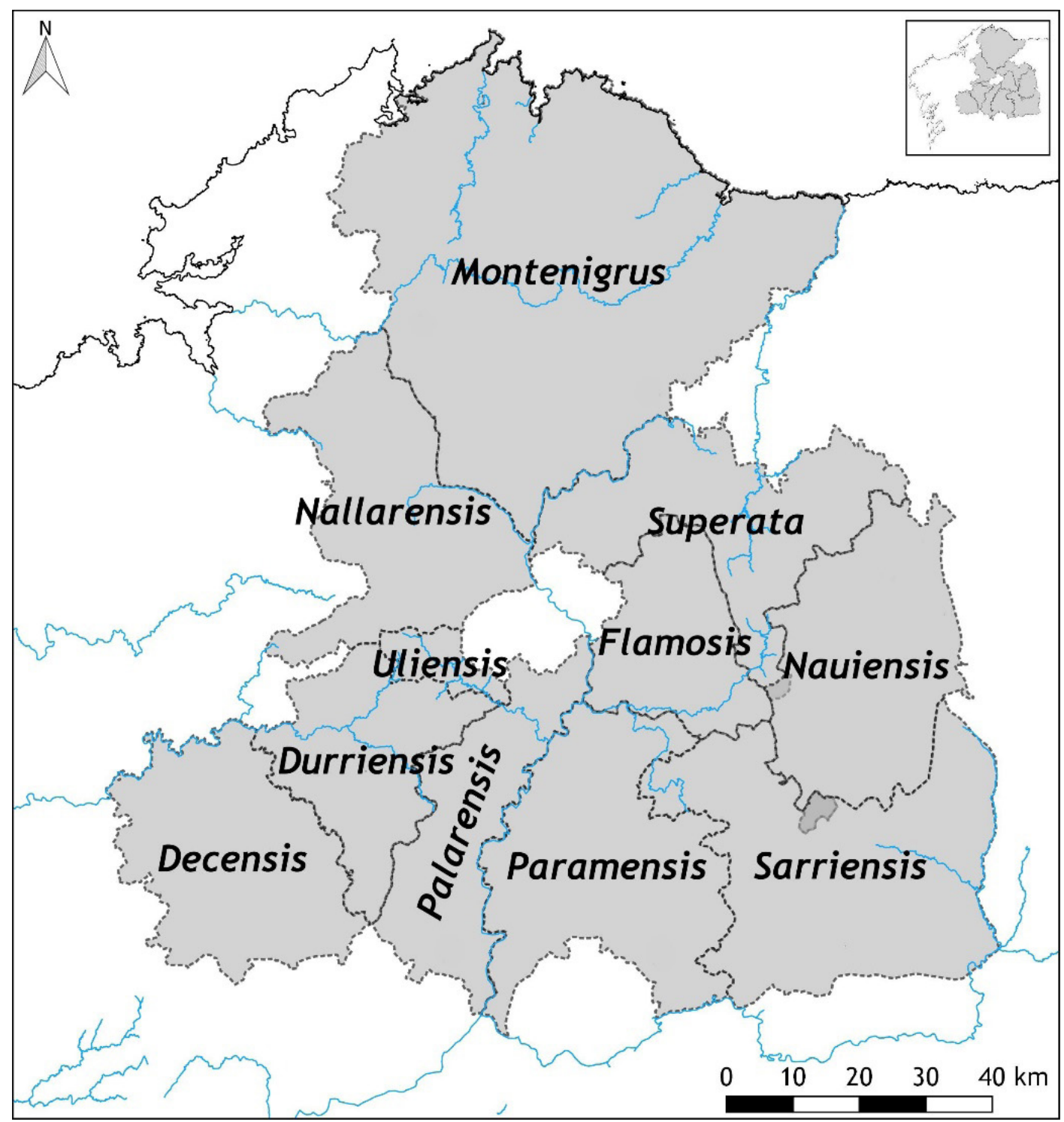

4. UNA LECTURA EN POSITIVO: LOS ONCE COMITATUS DE LUGO

Como permite comprobar la figura 1, los once condados se extendían por el espacio de lo que en época moderna es la diócesis de Lugo y buena parte de la de Mondoñedo. La diferencia entre estos y los arciprestazgos posteriores queda patente al comparar cifras: once condados frente a más de cincuenta arciprestazgos, tal y como se resume en la tabla 3. 
Tabla 3. Relación entre los comitatus y los arciprestazgos de época moderna ${ }^{29}$

\begin{tabular}{|c|c|}
\hline Flamosis & $\begin{array}{c}\text { Farnadeiros, Neira de } \\
\text { Jusa, Maestrescolía y } \\
\text { Bolaño, y Sarria y Luaces } \\
\text { de manera parcial. } \\
\text { Algunas parroquias de los } \\
\text { Cotos de Lugo }\end{array}$ \\
\hline Superata & $\begin{array}{c}\text { Aguiar y Azúmara } \\
\text { (Mondoñedo), Burón } \\
\text { (Oviedo), y Aguiar, } \\
\text { Luaces y Val de Pedroso } \\
\text { parcialmente. Algunas } \\
\text { parroquias de los Cotos de } \\
\text { Lugo }\end{array}$ \\
\hline Nauiensis & $\begin{array}{c}\text { Cervantes y Ferreiros. } \\
\text { Algunas parroquias de } \\
\text { Neira y Valcárcel }\end{array}$ \\
\hline Sarriensis & $\begin{array}{c}\text { Triacastela, Samos, } \\
\text { Valcárcel, Courel. Sarria } \\
\text { parcialmente }\end{array}$ \\
\hline Paramensis & $\begin{array}{c}\text { Páramo, Paradela, Incio, } \\
\text { Santalla de Rei, Saviñao y } \\
\text { Sardiñeira. Una feligresía } \\
\text { de Val de Ferreira }\end{array}$ \\
\hline Palarensis & $\begin{array}{c}\text { Pallares, Ferreira, } \\
\text { Monterroso, Taboada, } \\
\text { Chantada y Castro } \\
\text { Bermún }\end{array}$ \\
\hline Decensis & $\begin{array}{l}\text { Trasdeza, Deza y Dozón. } \\
\text { Piloño e Ínsoa de Loño } \\
\text { (Santiago de Compostela) }\end{array}$ \\
\hline
\end{tabular}

29 Solamente se indica la diócesis cuando el arciprestazgo no pertenece a Lugo. Para la comparativa con los arciprestazgos de época moderna se han utilizado distintas fuentes.

Diócesis de Lugo: A. García Conde y A. López Valcárcel, Episcopologio lucense, Lugo, Fundación Caixa Galicia, 1991; T. López, Mapa general del Obispado de Lugo, 1768, http://bibliotecadigital.rah.es/dgbrah/es/ consulta/registro.cmd?id=12890 (Consulta: 12-11-2018).

Diócesis de Santiago: J. del Hoyo, Memorias del Arzobispado de Santiago, edición preparada por Á. Rodríguez González y B. Varela Jácome, Santiago de Compostela, Porto y Cía. Editores, [1950?]; M. Vázquez Bertomeu, A Igrexa de Santiago contra 1500: O Libro do Subsidio, Noia, Lóstrego, 2003.

Diócesis de Mondoñedo: E. Cal Pardo, Colección diplomática medieval..., doc. 206, pp. 426-439.

Diócesis de Santiago y Mondoñedo: T. González (ed.), Censo de población de las provincias y partidos de la Corona de Castilla en el siglo XVI, Madrid, Imprenta Real, 1829, https://jcyl.es/es/consultbibliotecadigitala/ registro.cmd?id=7823 (Consulta: 13-12-2018). 


\begin{tabular}{|c|c|}
\hline Durriensis & $\begin{array}{c}\text { Abeancos, Ulloa y Ventosa } \\
\text { y Reboredo. Monterroso } \\
\text { parcialmente }\end{array}$ \\
\hline Uliensis & $\begin{array}{l}\text { Algunas parroquias de } \\
\text { Ulloa, Monterroso, Narla, } \\
\text { Parga y Gaioso }\end{array}$ \\
\hline Nallarensis & $\begin{array}{l}\text { Parga (Mondoñedo), } \\
\text { Narla, Parla, Gaioso y } \\
\text { Abeancos parcialmente. } \\
\text { Algunas parroquias de } \\
\text { Pruzos (Santiago de } \\
\text { Compostela) }\end{array}$ \\
\hline Montenegrinus & $\begin{array}{c}\text { Riba de Miño y } \\
\text { Entrambasaugas, } \\
\text { Ortigueira, Viveiro } \\
\text { y Azúmara, parte } \\
\text { de Cedeira, y } \\
\text { administraciones de } \\
\text { Ribera de Sande, Bretoña, } \\
\text { Vilamaior y San Miguel } \\
\text { (Mondoñedo). Deanazgo, } \\
\text { Chantría, Mestrescolía, } \\
\text { parroquias dependientes } \\
\text { de la mesa episcopal } \\
\text { mindoniense }\end{array}$ \\
\hline
\end{tabular}

La descripción comienza en el comitatus Flamosis, situado al este de la sede catedralicia. Son diecisiete las referencias geográficas que la componen y once las identificadas en este trabajo, que dan pie a la reconstrucción de su perfil. De entre todas ellas resulta especialmente significativo el detalle con el que se describe el límite oeste que la separa de Lugo. Siguiendo los datos recogidos en la tabla 2 los orónimos son los más repetidos (cinco), seguidos de dos villae y un villare. El fragmento correspondiente a esta entidad se inicia con la mención de dos hidrónimos, oritur ubi intrat flumen Neira in Mineo; a ellos es posible que se una un tercer río, Elebrone, aunque la imposibilidad de identificación exacta hace que sea clasificado como dudoso. Están presentes también dos topónimos, más una penna, una petram, un túmulo o mamola y una fuente, lo que supone que hasta siete categorías distintas de las identificadas en la tabla 2 se combinan para reconstruir la forma de la circunscripción.

El comitatus Superata destaca por el detalle de la descripción, con un total de diecinueve referencias de las que se han podido identificar catorce, que permiten reconstruir un condado de perfil complejo tal y como se refleja en la figura 1. De nuevo orónimos e hidrónimos son los elementos más veces repetidos, tres en cada caso, y a estos los acompañan dos pennas, dos petras, dos fuentes, dos villae, un locus, un campo y un puerto, más dos topónimos. Presenta por tanto una considerable variedad en cuanto a la tipología de estos elementos, ya que están presentes nueve de las diecisiete identificadas en la tabla 2. 
El comitatus Nauiensis parte nuevamente de un hidrónimo, el del río Navia, para dibujar un distrito de marcado carácter montañoso en el que no sorprenden los múltiples orónimos, con cinco referencias a montes en el macizo lucense, el Bierzo leonés y el valle asturiano de Ibias; a ellas se suman una peña y una ambigua mención a los Ancares lucenses. La descripción incluye también cuatro topónimos, destacando el de Paturnello, interpretado para la confección del mapa como Piornedo (Cervantes), ya que Padornelo (Pedrafita do Cebreiro) se encuentra en la dirección opuesta a la que sigue la relación.

El comitatus Sarriensis es el que presenta la forma más forzada de todos, dejando al valle del río que le da nombre en posición excéntrica y desarrollándose por todo el macizo montañoso, llegando a la cuenca del Burbia, ya en el Bierzo. Hasta la desembocadura de este en el Sil, todo es diócesis de Lugo.

La mención aquí al puente de Villafranca, un topónimo cuya primera referencia conocida es del $1120^{30}$, puede estar en relación con el conflicto con la diócesis de León por las iglesias de Navia, Triacastela y Valcárcel ${ }^{31}$. No obstante, la versión del Liber Fidei de Braga omite esta idea ${ }^{32}$, con lo que probablemente haya sido añadida a modo de aclaración en el momento de la confección del Tumbo Viejo.

Los orónimos son los grandes protagonistas de este condado, contándose cinco montes o peñas en su límite noreste y otros cuatro en el cierre meridional. Uno y otro suman igualmente cuatro topónimos, entre ellos Paturnello y Cairoga. El primero forma parte de la redundancia en la descripción del límite con el condado naviense, mientras el segundo supone el recurso a una de las tres protoparroquias comunes al texto inicial.

En el caso del comitatus Paramensis el elemento vertebrador (Páramo) no es un hidrónimo sino lo que podría parecer un orónimo, si bien N. Ares Vázquez lo identificó como un teónimo ${ }^{33}$. Con todo, es la confluencia del Neira y el Sarria el elemento de separación con los territorios metropolitanos, continuando el límite septentrional con un castro, un monte y un topónimo. El límite sur es particularmente prolijo en referencias geográficas de origen antrópico: tres castros, otros tantos topónimos (incluyendo nuevamente Quiroga) y un puerto, el de Pombeiro, en el río Sil. A ellos se suman cinco orónimos y un elemento no identificado.

Ningún tipo de accidente geográfico parece dar nombre al comitatus Palarensis, sino un topónimo presente en la actualidad en tres parroquias del municipio de Guntín. Su territorio está singularmente bien definido por el cauce del Miño, desde la desembocadura del Argonde y hasta la del Sil. En el flanco opuesto los elementos de linde son más heterogéneos, con tres orónimos, otros dos hidrónimos y tres castros.

Una mención específica requiere Eirosum Montem, que por coherencia geográfica debería de ser Monterroso. Poco factible desde la perspectiva lingüística, de ser así se trataría probablemente de un intento por hacer parecer más antiguo el nombre.

El perfil del comitatus Decensis es descrito en el documento a través de nueve referencias, todas ellas identificadas. Destaca el peso de los orónimos con la presencia de cuatro montes y un puerto, a los que acompañan los ríos Ulia y Arnego, así como un puente

30 M. Durany Castillo y C. Rodríguez González, "El paisaje urbano de Villafranca del Bierzo en la Edad Media", en Humanitas: estudios en homenaxe ó Prof. Dr. Carlos Alonso del Real, Santiago de Compostela, Universidade de Santiago de Compostela, Servicio de Publicacións e Intercambio Científico, 1996, p. 476.

31 1164. El Papa Alejandro III insiste en la restitución a Lugo de Triacastela, Navia y Valcárcel, en manos del obispo de León. En J. L. López Sangil y M. Vidán Torreira, “Tumbo Viejo...”, doc. 93, pp. 192-193.

32 A. de J. da Costa (ed.), Liber Fidei Sanctae Bracarensis Ecclesiae, Braga, Assembleia Distrital, 19651978, vol. I, doc. 11, pp. 19-24.

33 N. Ares Vázquez, “Toponimia do Concello do Páramo”, Lucensia, 16 (1998), pp. 95-110. 
sobre el primero de ellos y el topónimo Summio, que no va acompañado de ninguna otra especificación.

Entre los límites de Deza y el curso del Ulla sitúa el texto el comitatus Durriensis, referencia directa a un topónimo, la actual parroquia de Santiago de Dorra (Antas de Ulla). El flanco restante se determina mediante cinco orónimos, otros tantos castros, cuatro topónimos, una mamola, y los ambiguos Portellam de Linares y Cruces inter Uliola et Durria.

El condado de menores dimensiones de todos es el Uliensis, con poco más de $100 \mathrm{~km}^{2}$ según la reconstrucción realizada a partir de una breve relación formada por seis elementos distribuidos equitativamente entre los tres más frecuentes en el documento: dos orónimos, dos topónimos y dos hidrónimos.

Catorce son las referencias utilizados para describir el comitatus Nallarensis, con una diferencia con respecto a los restantes ya que se indican dos entidades, y no dos lugares concretos, como límites por el oeste: uadit ad terminos de Montanos et Durmiana. Se mencionan también cuatro hidrónimos, dos orónimos, un castillo, un puente y tres topónimos.

Cierra esta parte del documento el comitatus Montenegrinus, cuya extensión representa más de un cuarto del total del territorio en él delimitado. Frente a esto la descripción no es de las más prolijas, con doce referencias que se reparten entre cinco orónimos, cuatro hidrónimos, un puente y dos topónimos. Por medio de una serie de elementos que parecen haber sido cuidadosamente seleccionados, el obispado de Lugo se apropia de buena parte del territorio perteneciente a Mondoñedo, que reclama para sí mismo bajo la forma del indicado condado. Aparece delimitado por tres ejes: de la desembocadura del Ladra en el Miño a Ortigueira por el oeste; desde el mismo punto a la unión del Eo con el mar Cantábrico por el este; y de Ortigueira a la desembocadura del Eo en el mar por el norte, es decir, toda la franja cantábrica gallega.

Quizás haya que entender esta apropiación espacial por el hecho de que Montenegro era, de los arciprestazgos y arcedianazgos de Mondoñedo, el más próximo a la sede catedralicia y a la ciudad de Lugo. Esta cercanía podría haber motivado que se diera el nombre de la entidad (presente también en la organización civil del territorio) a casi la totalidad de la diócesis mindoniense que Lugo ansiaba controlar.

Frente a esto la documentación presenta un escenario bastante distinto en el que la voluntad apropiadora de Lugo no habría surtido efecto, como pone de manifiesto la composición que en el año 1128 hace el monarca Alfonso VII entre el obispo de Mondoñedo y el conde Rodrigo Vélaz ${ }^{34}$. En dicho diploma se identifican las parroquias pertenecientes a cada uno, encuadradas en sus respectivas terrae; entre ellas figuran la iglesia de sancta Maria de Montenigro y la terra de Montenigro, esta última de dimensiones claramente inferiores al condado descrito en el documento, cuyo espacio aparece aquí fragmentado en varias circunscripciones.

\section{UNA LECTURA EN NEGATIVO}

\subsection{El entorno catedralicio: vacíos en el espacio central diocesano}

Destaca, sin duda, el vacío en torno al núcleo de la diócesis: no se detallan los términos de la propia catedral, sino que estos se marcan en negativo; la definición de los límites de los condados que la rodean determina el perfil del territorio inmediato de la civitas lucense.

A este se une otro quizá menos llamativo pero igualmente significativo si se tienen en cuenta los condicionantes documentales: la ausencia del comitatu Mera, cuyas tres cuartas

34 E. Cal Pardo, Colección diplomática medieval..., doc. 11, pp. 24-27. 
partes fueron donadas por el rey Bermudo II a la iglesia lucense en el año $991^{35}$. Más allá de este documento y las copias conservadas (en el tumbo de Sobrado, entre otras ${ }^{36}$ ), interesa una confirmación de las posesiones de Lugo hecha por el rey Alfonso V; el año que figura en el diploma es 1027, aunque los estudios realizados tienden a señalar su falsedad o interpolación y llevan su datación hasta finales del siglo XI, entre 1070 y $1078^{37}$. En él se describen los límites de Mera:

[...] Quomodo se separat ille Comitatu de Mera de illos alios Comitatos de Narla et de Ferraria, de Argunde quod nuncupant Palliares et sunt certi suis terminis et diuisiones quod Nos per memoria hominum et per actos stilo exaramus et sigillatim nominanus: $[\ldots]^{38}$.

Tras la enumeración de los condados con los que limita, algunos de los cuales figuran entre los once de Tempore suevorum (Narla, Palliares), prosigue con una detallada descripción del término de Mera hito a hito, hasta trazar su perímetro por medio de referencias a distintos elementos del paisaje (natural y habitado) como portelas, cerros, altos, ríos o villas, entre otros ${ }^{39}$. Una sentencia del rey Alfonso $\mathrm{VI}$ a un pleito entre el obispo Vistruario de Lugo y los condes Vela y Ovéquiz del año 1078, copiada en el mismo cartulario ${ }^{40}$, reproduce literalmente ciertas partes del documento con fecha 1027. Esta coincidencia lleva a pensar que ambos hayan sido elaborados en la década de los 70 del siglo XI y no a inicios de este, en un contexto de gran interés para la diócesis de Lugo en el que desde dicha sede se promueve la producción de falsos para hacer valer sus derechos territoriales sobre obispados vecinos, y en el que probablemente se redactó también la descripción de los once condados.

Aunque, como sucede con el documento Deo omnipotenti, no es posible identificar todos los puntos de la relación, sí se localizan los suficientes como para proponer un perfil aproximado de su extensión. Al superponer esta reconstrucción con el mapa de los condados se comprueba cómo Mera según la descripción del texto de 1027/1078 encaja casi a la perfección en uno de los vacíos.

El condado de Mera quedaría encuadrado entre los de Pallares, Ulla y Narla; al este el río Miño marca la frontera con Lugo y su catedral. ¿Sería posible que el autor del documento Deo omnipotenti conociese la existencia de los dos copiados en el Tumbo de Lugo en los que se describe Mera, y por ello respetase deliberadamente los límites de un condado que no aparece citado entre los once de Tempore suevorum, pero que estaba en manos del obispo de Lugo tras una donación regia? Todo parece indicar que sí, y por tanto la ausencia de Mera respondería al hecho de que el documento en el que se describen los once condados fue realizado con posterioridad a la sentencia de Alfonso VI, al igual que la propia interpolación en Tempore suevorum.

35 J. L. López Sangil y M. Vidán Torreira, “Tumbo viejo...”, doc. 14, pp. 63-64.

36 P. Loscertales de García de Valdeavellano, Tumbos del monasterio de Sobrado de los Monjes, Madrid, Archivo Histórico Nacional, 1976, vol. I, doc. 107, pp. 127-130.

37 "Como han demostrado agudamente los editores del original, la copia del Tumbo viejo y las del Tumbo nuevo, de ella dependientes, son evidentes falsificaciones, que pueden fecharse, casi con total seguridad, entre los años 1070 y 1078 [...]" [en negrita en el original]. M. R. García Álvarez, "Catálogo de documentos reales de la Alta Edad Media referentes a Galicia (714-1109) (Continuación)”, Compostellanum, vol. XI, 2 (1966), pp. 274-275.

38 J. L. López Sangil y M. Vidán Torreira, "Tumbo viejo...”, doc. 10, pp. 55-58.

39 Ibídem, doc. 10, pp. 55-58.

40 Ibídem, doc. 81, pp. 170-174. 
Figura 2. Ausencias: el comitatu Mera

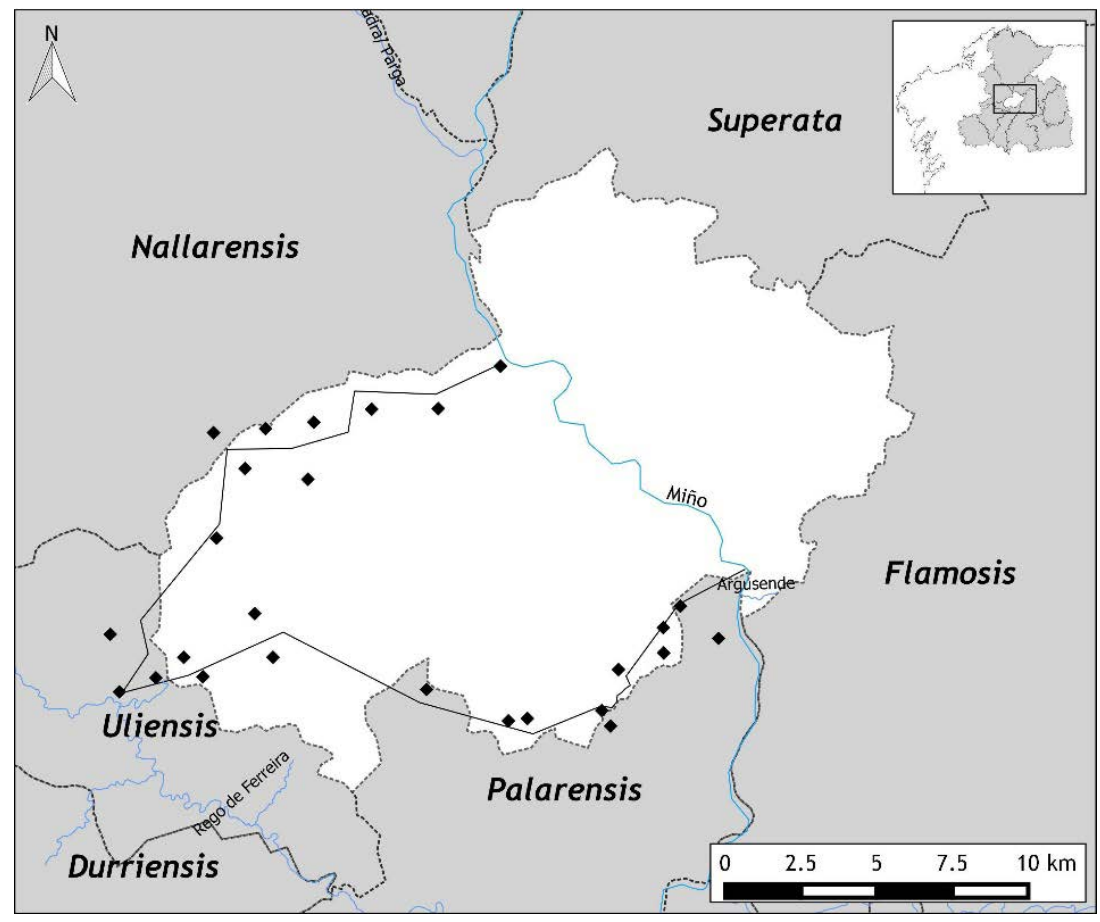

\subsection{Los vacíos meridionales}

Las fronteras meridionales del comitatus Sarriensis discurren justo al norte del núcleo leonés de Cabarcos, recorriendo la orografía local hasta el valle de Quiroga. Al hacerlo dejan un vacío impreciso que se extiende en el entorno del cauce del Sil, de modo muy semejante a como lo hace el mapa moderno al situar en este lugar los términos de la abadía cluniacense de Villafranca y la encomienda sanjuanista de Quiroga, ambas insertas en la Edad Moderna en la diócesis de Astorga ${ }^{41}$.

En este ambiguo espacio parecen situarse, consecuentemente, la suma de dos de las tres protoparroquias consignadas a la iglesia lucense al margen de su adyacencia: Cabarcos y Cairoga. Si la localización de esta última ofrecía pocas dudas, dada su aparición como elemento fronterizo en las descripciones de Sarria y Páramo, la primera pasa a situarse necesariamente en torno a Cabarcos (Sobreda, León), toda vez que las opciones del norteño Cabarcos (Barreiros, Lugo) se difuminan al quedar englobado en los términos descritos para el condado de Montenegro.

Curiosamente, Lugo no parece particularmente interesado en ninguno de estos dos espacios y, a diferencia del resto de casos, no usará su aparición en ambos documentos para los pleitos con otras sedes ${ }^{42}$. No en vano, será Astorga la demandante de Quiroga, con

41 Así lo muestra la información cruzada entre T. López, Mapa general del obispado de Lugo... y T. González (ed.), Censo de población de las provincias y partidos...

42 No en vano, Lugo será una excepción en el amplio listado de pleitos sostenidos por Astorga: con Salamanca por Zamora y Toro, Braga por Braganza y Aliste, y Ourense por Trives y Robleda. En A. Quintana Prieto, El Obispado de Astorga en el siglo XII, Astorga, Publicaciones del Archivo Diocesano de Astorga, 1985, pp. 48-55. 
un supuesto documento de Ramiro II ${ }^{43}$, extremo que parece ser ya una realidad en $1201^{44}$. Más extraño resulta el caso de Cabarcos, completamente ausente de la documentación, lo que sugiere que tal vez ya no fuera una realidad tan identificable en el siglo XI, extremo únicamente viable si su referencia es genuina. En el siglo XVI esta parroquia aparece inserta dentro del arciprestazgo de Valdeorras de la diócesis asturicense ${ }^{45}$.

De manera análoga, la cuidada descripción de los límites del comitatus Paramensis dibuja un último vacío encerrado por este último y el río Sil. Se trata sin embargo de la única coincidencia, pues en este caso se perfila un hueco redondeado y singularmente bien definido, que encaja con buena parte de la actual tierra de Lemos y con los arciprestazgos modernos de Monforte, Amandi y Val de Ferreira. La sustracción parece sencilla y, en virtud de ella, Seuios ha de ser Lemos. Esta no es una idea nueva y, de hecho, ya fue completamente asumida por los editores del propio Tumbo Viejo ${ }^{46}$. Es igualmente la tesis defendida por J. C. Sánchez Pardo, aludiendo además a la interesante aparición de Lemos en lugar de Seuios en la versión A de Tempore suevorum ${ }^{47}$.

Tal vez Seuios pueda entenderse como un irónico testimonio de veracidad, dado que ni la mitra ni ninguna otra institución obtenían ningún beneficio de acuñar un nombre inexistente. Todo apunta a un error de transcripción cometido en Lugo a partir de la lectura de documentos antiguos, quizás alguno del siglo $\mathrm{VI}^{48}$. Además, Lemos cuenta con varios argumentos que lo reivindican como protoparroquia. De un lado, el nombre, que alude al pueblo Lemavo $^{49}$, siendo bien conocido el vínculo entre entidades protohistóricas y ecclesiae tardoantiguas, en una continuidad que a menudo confluye en los arciprestazgos plenomedievales ${ }^{50}$. Del otro, el papel del abad del monasterio de San Vicente del Pino, arcediano de Monforte con silla propia en el coro lucense ${ }^{51}$, en la celebración de las letanías, tras la cual los sacerdotes del arcedianato accedían a la cámara abacial para un capítulo de corrección de costumbres ${ }^{52}$.

El vacío podría encajar con el arcedianato de Monforte. Este estaba formado en el siglo XVI por el arciprestazgo homónimo y las administraciones de Amandi, y Saviñao y

43 934. Ramiro II concede a la sede de Astorga los lugares de Berganza, Aliste, Sanabria, Tribes, Caldelas, Caurelle, Quiroga, lurres. En G. Cavero Domínguez y E. Martín López, Colección documental de la Catedral de Astorga, León, Centro de Estudios e Investigación "San Isidoro", Caja España de Inversiones, Archivo Histórico Diocesano, 1999, vol. I, doc. 40, pp. 92-93.

44 Alfonso IX concede la exención del yantar real a los hombres de Astorga en Robreda, Tribes, Caldelas y Quiroga. En G. Cavero Domínguez y E. Martín López, Colección documental..., vol. II, doc. 967, pp. 244-245.

45 T. González (ed.), Censo de población de las provincias y partidos..., p. 176.

46 No en vano corrigen la forma Seuios por Lemos en la nota 108 de la edición de Tempore suevorum en J. L. López Sangil y M. Vidán Torreira, "Tumbo viejo...", doc. 7, p. 48.

47 J. C. Sánchez Pardo, "Organización eclesiástica...", p. 445.

48 En opinión de J. L. López Sangil y M. Vidán Torreira, coherente con lo defendido por P. David, en los dos textos puestos en circulación por Lugo se encuentra la traza de numerosos documentos auténticos.

49 Mencionado por Plinio en la Naturalis Historia y las tablas de Ptomoleo, unas treinta millas al sur de Lugo. En E. Pardo de Guevara y Valdés, Los señores de Galicia. Tenentes y Condes de Lemos en la Edad Media, A Coruña, Fundación Pedro Barrié de la Maza, Instituto de Estudios Gallegos "Padre Sarmiento" CSIC, 2000, vol. I, p. 49.

50 M. Fernández Calo, "Plinio, o parroquial suevo, e a evolución estrutural do poder local galaico na Antigüidade", Gallaecia: revista de arqueoloxía e antigüidade, 34 (2015), p. 176.

51 E. Pardo de Guevara y Valdés, Los señores de Galicia..., vol. I, p. 53.

52 Esta costumbre aparece citada en el s. XIX en R. R. Vilariño de Barbeito, Monforte, sus monumentos, leyendas y tradiciones, Monforte de Lemos, El eco de Lemos, 1896, pág. 24-28. Para F. López Alsina, "Da protoparroquia...", p. 59, este tipo de reuniones recordarían las de los clérigos con el abad protoparroquial. 
Sardiñeira. El arcedianato de Sarria poseía, a modo de isla, la de Val de Ferreira ${ }^{53}$. Dado que esta última no aparece en la documentación hasta la Baja Edad Media ${ }^{54}$ y nunca figura en los listados de parroquias reclamadas por Lugo, a diferencia de Lemos -Monforte-, Verosmos -Amandi- y Saviñao, tal vez aún no existiera. En este caso, para que el vacío dejado por el parroquial coincidiera con el arcedianato, apenas sería preciso que Saviñao no dependiera a la sazón de él.

La ausencia de la palabra Lemos no debió de pasar desapercibida para sus contemporáneos, pues solo así se explica que Ourense, a pesar de basarse en el propio parroquial para reconstruir sus términos, transgreda la frontera del Sil y demande Lemos como parte integrante de su diócesis ${ }^{55}$. La diferente actitud lucense con respecto a Quiroga y Cabarcos se aprecia aquí en su indisimulada determinación a defender su imperio sobre este territorio, sosteniendo un pleito que se extenderá hasta finales del siglo XII, siendo finalmente zanjado en beneficio lucense por el Papado. Entonces el Pontífice se refiere a las parroquias de Lemos y Verosmos como el objeto de disputa ${ }^{56}$, es decir, justamente el territorio contenido en el hueco de Seuios.

En este lugar había una cuarta institución intentando terciar en el conflicto: el cenobio de San Vicente del Pino (Monforte de Lemos). En un nuevo documento falso defiende haber sido reconocido con una diocesis uere nullius, especificando el espacio sobre el que la ejercería (ver figura 3), y remitiendo para ello a Alfonso II, el monarca que, supuestamente, había dado varias parroquias del sur lucense a la iglesia asturiana ${ }^{57}$. El distrito resultante, ligeramente encabalgado con el comitatus Paramensis, tiene importantes parecidos con el arciprestazgo monfortino, si bien lo excede en casi todos sus puntos.

Esta institución está probablemente en el origen del detallado límite sur del condado paramense. Puede ser también un indicador de la batalla que la sede está dispuesta a dar con los monasterios, no mencionando a Samos, limitando a San Vicente del Pino, y reivindicando específicamente Pombeiro. A fin de cuentas, con la reforma de la iglesia leonesa llevada a cabo bajo el reinado de Fernando I, los obispos buscaban también afirmarse sobre los monasterios ${ }^{58}$.

53 N. Peiró Graner, EI Señorío Episcopal lucense en el siglo XVI. Estructura y administración, Lugo, Servicio de Publicaciones Excma. Diputación Provincial de Lugo, 1998, pp. 293-295.

54 Tal vez la primera referencia haya que verla en 1236 en la fórmula tenente ecclesias de Ferraria archidiaconus Petris Sebastianus, en J. I. Fernández de Viana y Vieites, Colección diplomática del monasterio de Santa María de Ferreira de Pantón, Lugo, Excma. Diputación provincial de Lugo, 1994, doc. 11, pp. 26-27. En 1342, sin embargo, se registra la primera mención al arciprestazgo de Val de Ferreira (M. J. Portela Silva, Documentos da Catedral de Lugo. Século XIV, Santiago de Compostela, Consello da Cultura Galega. Sección de patrimonio histórico, 2007, vol. I, doc. 434, pp. 471-472).

55 F. López Alsina, "El Parrochiale Suevum...", p. 108.

56 [1184-85]. Lucio III comunica al obispo lucense la sentencia del pleito que mantenía con Ourense. En J. L. López Sangil y M. Vidán Torreira, “Tumbo viejo...”, doc. 101, pp. 203-205.

57 M. R. García Álvarez, "En torno a los orígenes del Monasterio de San Vicente del Pino", Boletín de la Comisión Provincial de Monumentos Históricos y Artísticos de Lugo, vol. 5, 37-38 (1952), pp. 80-90. Véase la transcripción del documento en C. Rodríguez Fernández, La colección diplomática de San Vicente del Pino, Tesis doctoral inédita, Granada, Facultad de Filosofía y Letras, 1990, doc. 1, pp. 234-236, http://cirp.es/ codolga/files/san_vicente_do_pino.pdf (Consulta: 07-05-2019).

58 F. López Alsina, "El Parrochiale Suevum...", p. 116. 
Figura 3. La diócesis uere nullius demandada por San Vicente del Pino

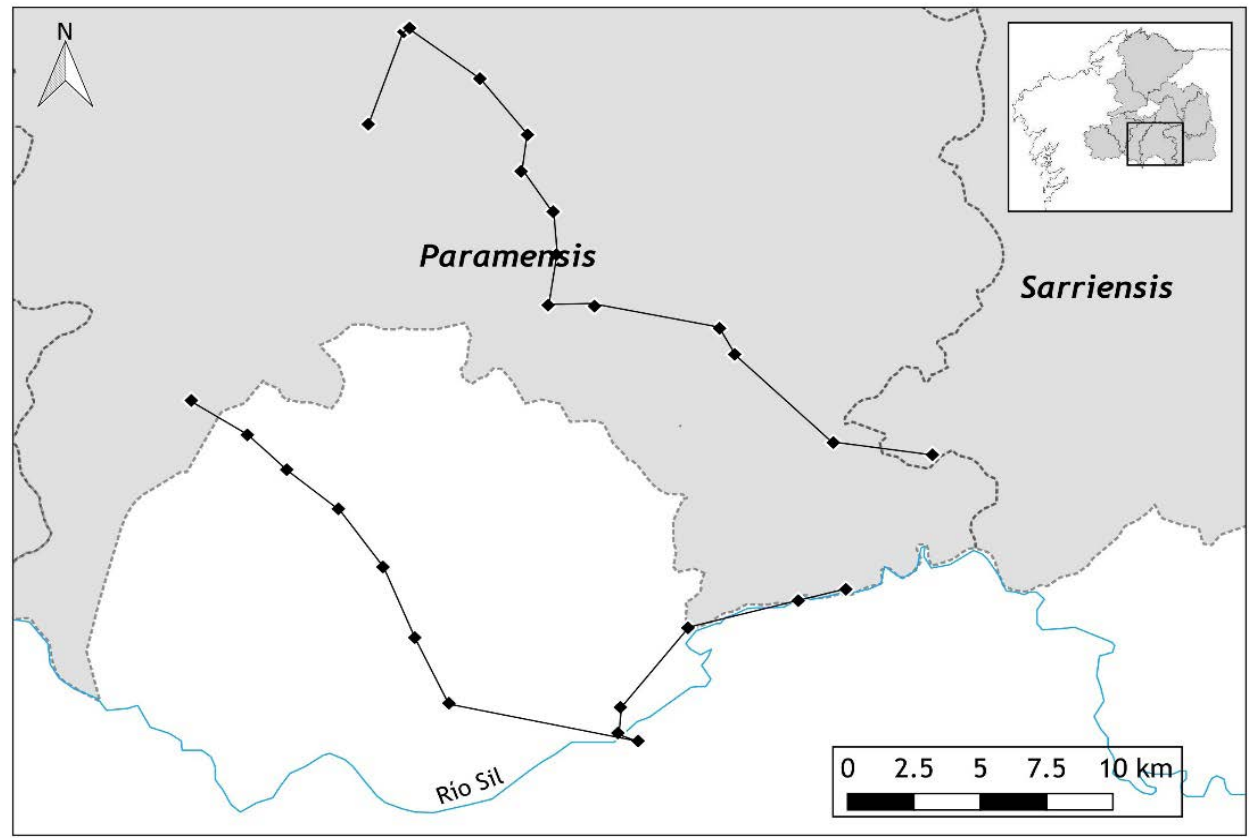

\section{CONCLUSIONES}

El documento analizado en las páginas precedentes se mueve entre dos cronologías, y es el resultado de la confluencia de factores diversos como las distintas transmisiones de una fuente escrita del siglo $\mathrm{VI}$, el contexto político y religioso cambiante de cinco siglos después o las ambiciones de varios obispos. Como sostiene F. López Alsina, en el siglo $\mathrm{XI}$ los responsables de las diócesis del noroeste peninsular recuperan un texto del siglo VI y se valen de él para defender sus respectivos intereses, en un momento en el que sus espacios diocesanos se veían amenazados por la restauración de las sedes meridionales de Tui, Ourense y Braga ${ }^{59}$.

Frente a lo que sucede con el resto de sedes, para las que se enumeran una serie de eclesias y pagi, en el caso de Lugo todas las versiones de Tempore suevorum recogen una adyacencia distribuida en once condados más Carioca, Seuios y Cavarcos. La intervención no se limita a la alteración del texto del siglo Vl, y así una carta que se hace pasar por coetánea desarrolla estos distritos, dejando al margen los tres anteriores.

Al entender que ambos textos fueron confeccionados de manera simultánea y obedeciendo a un mismo fin, la comprensión espacial de la adyacencia lucense en Deo omnipotenti explica los objetivos últimos contenidos en Tempore suevorum. La interpretación de este se encontraba hasta la fecha limitada por la poca atención prestada a aquel, capaz sin embargo de ofrecer múltiples lecturas. La suma de ambos permite una mejor aproximación al fenómeno del Parrochiale, de modo tal que, aun cuando los límites cartográficos no son todo lo precisos que podrían ser, queda clara la intención de Lugo de defender un espacio diocesano compacto, resultado del agregado de los once condados descritos.

La falsificación operada en ambos textos nos impide conocer la distribución real de la diócesis. Por algún motivo, la interpolación no afecta a las tres protoparroquias citadas, que tienen amplias posibilidades de ser ciertamente antiguas. Al menos para los autores del siglo XI, esos tres lugares eran sin duda Lemos, Quiroga y Cabarcos (León), como 
demuestra claramente el que sean los únicos lugares no cubiertos por los once espacios descritos, junto a la ciudad Lugo y Mera. Así, a lo que dice explícitamente el documento se suma lo que se manifiesta en negativo y que no puede verse salvo gracias a la cartografía.

Si entendemos el Tempore suevorum como la plasmación de la reorganización de las diócesis del reino suevo en el siglo VI, la descripción de los condados vendría a ser un elemento más; así como las otras sedes ven detalladas sus ecclesias, protoparroquias de una extensión muy superior a las del periodo plenomedieval, Lugo opta por la fórmula de los comitatus, a los que atribuye dimensiones aún mayores. Reclama para sí su adyacencia y le da la forma que más le beneficia, al tiempo que reivindica sus derechos sobre la diócesis mindoniense y la recién restaurada auriense.

Los espacios dibujados en Deo omnipotenti no coinciden con el mapa de arciprestazgos posteriores, ni con las iglesias señaladas por Alfonso II. Tampoco parece probable que remitan a realidades ciertamente antiguas, con la sola posible excepción de las tres protoparroquias. El uso extensivo de orónimos e hidrónimos, así como referencias a castros y monumentos megalíticos, podrían mostrar una deliberada voluntad de dibujar espacios diferentes a los vigentes en el siglo XI pero a su vez perfectamente reconocibles para un lector del momento, haciendo más fácil su asimilación al siglo VI. El éxito de esta estrategia queda probado al ser posible su reconstrucción e interpretación desde la actualidad.

Finalmente, Alfonso VII concede a Lugo todo aquello que había pedido en el flanco central y meridional: Neira superior e inferior, Valonga, Flamoso, Sarria, Froilanos, Lemos, Verosmos, Sauinianos, Paramos, Asma, Camba, Dezón y Auiancos ${ }^{60}$. Con la consecución, décadas más tarde, de las parroquias discutidas por León, Lugo logra un rotundo éxito en sus aspiraciones meridionales, alcanzando la diócesis que deseaba, desde el Burbia y hasta el Iso. El interés por Lemos y Verosmos parece haber aumentado desde los documentos del obispo Amor, al contrario que en los casos de Quiroga y Cabarcos, por los que la sede lucense no parece dispuesta a luchar con Astorga.

Bien distinto es el resultado en el norte, donde la integridad de Mondoñedo no se resiente. Sin embargo, dado el descompensado esfuerzo invertido entre el ataque a esta sede y el mostrado contra Oviedo y León, tal vez deba considerarse una derrota esperada.

Muy notable resulta que Lugo en ningún momento arremete contra las dos diócesis tardoantiguas con las que limita: Iria y Astorga (ni a Oviedo como heredera de la parte ultramontana asturicense). Todo su despliegue documental busca la confrontación con las diócesis que no podían poseer territorios en el siglo VI: León y Oviedo, con lo que, pese a las interpolaciones, podría estar transmitiendo las dimensiones reales que la documentación antigua recogía. Más espinoso es llevar la misma lectura hacia el norte, donde ciertamente Mondoñedo podría no haber tenido una entidad territorial. En este sentido, la lógica geográfica beneficia a la sede lucense, pues si Astorga, aun a pesar de la cordillera, e Iria alcanzaban el mar (dando por válidas las pretensiones ya comentadas de esta última), el mismo sentido tendría que lo hiciera Lugo, lo que le daría unos límites entre el Sil y el Cantábrico. En el lado opuesto se sitúan los pocos datos descriptivos que aporta para el condado de Montenegro y las dimensiones que le otorga, muy semejantes a las de la diócesis mindoniense, lo cual no sugiere una lectura de documentos antiguos. No obstante, es preciso tener en cuenta que todo está supeditado a la comprensión del siglo XI, y tal vez Lugo estimara una simplicidad efectiva, en línea igualmente con los menores esfuerzos que demuestra en esta área.

60 1154. Alfonso VII da a la diócesis de Lugo los límites pretendidos y compensa a Oviedo con bienes de la corona. En J. L. López Sangil y M. Vidán Torreira, “Tumbo viejo...”, doc. 29, pp. 93-94. 
El mar como aspiración fronteriza parece haber sido una tónica compartida por varias de las diócesis del noroeste en los siglos XI y XII. Así, a las aspiraciones de Lugo, materializadas en el documento analizado, y las de Astorga, se unen también las de Iria con su disputa con Mondoñedo por el control de los arciprestazgos de la franja atlántica.

\section{BIBLIOGRAFÍA}

Álvarez Álvarez, C. y Cavero Domínguez, G., "La diócesis de Astorga, entre el reino de León y la sede de Braga", en Adão da Fonseca, L., Amaral, L. C. y Ferreira Santos, M. F. (coords.), Os reinos Ibéricos na Idade Média: livro de Homenagem ao Professor Doutor Humberto Carlos Baquero Moreno, Porto, Livraria Civilização, 2003, vol. I, pp. 337-339.

Arias, P., Historia del Real Monasterio de Samos, A Coruña, Libros Dixitec, 2011.

Aubrun, M., La paroisse en France: des origines au XVe siècle, París, Picard, 2008.

Cal Pardo, E., Colección diplomática medieval do arquivo da Catedral de Mondoñedo, Santiago de Compostela, Consello da Cultura Galega, 1999.

Castagnetti, A., La pieve rurale nell'Italia padana. Territorio, organizzazione patrimoniale e vicende della pieve veronese di San Pietro di "Tillida" dall'alto medioveo al secolo XIII, Roma, Herder, 1976.

Cavero Domínguez, G. y Martín López, E., Colección documental de la Catedral de Astorga, León, Centro de Estudios e Investigación "San Isidoro", Caja España de Inversiones, Archivo Histórico Diocesano, vols. I-II, 1999-2000.

Corpus Documentale Latinum Gallaeciae (CODOLGA), Santiago de Compostela, Centro Ramón Piñeiro para a Investigación en Humanidades, 14 (2017), http://cirp.gal/ codolga/ (Consulta: 07-05-2019).

David, P., Études historiques sur la Galice et le Portugal du VIe au XIle siècle, Lisboa, Institut Français au Portugal, 1947.

Díaz y Díaz, M. C., "Orígenes cristianos en Lugo", en Actas del Coloquio Internacional sobre el Bimilenario de Lugo, Lugo, Patronato del Bimilenario, 1977.

Díaz Martínez, P. de la C., "El Parrochiale Suevum: organización eclesiástica, poder político y poblamiento en la Gallaecia tardoantigua", en Mangas, J. y Alvar, J. (eds.), Homenaje a José $M^{a}$ Blázquez. Vol. VI Antigüedad: religiones y sociedades, Madrid, Ediciones Clásicas, 1998, pp. 35-47.

Domínguez Sánchez, S., "El papel de los legados y de los jueces pontificios en la lucha de los Obispados de León y Lugo por Triacastela", en Herbers, K., Engel, F. y López Alsina, F. (eds.), Das begrenzte Papsttum: Spielräume päpstlichen Handelns, Legaten, delegierte Richter, Grenzen, Berlín, De Gruyter, 2013, pp. 237-248.

Fernández Calo, M., "Plinio, o parroquial suevo, e a evolución estrutural do poder local galaico na Antigüidade", Gallaecia: revista de arqueoloxía e antigüidade, 34 (2015), pp. 175-207.

Fernández de Viana y Vieites, J. I., Colección diplomática del monasterio de Santa María de Ferreira de Pantón, Lugo, Excma. Diputación Provincial de Lugo, 1994.

García Álvarez, M. R., "En torno a los orígenes del Monasterio de San Vicente del Pino", Boletín de la Comisión Provincial de Monumentos Históricos y Artísticos de Lugo, vol. 5, 37-38 (1952), pp. 80-90.

- "Catálogo de documentos reales de la Alta Edad Media referentes a Galicia (714-1109) (Continuación)", Compostellanum, vol. XI, 2 (1966), pp. 257-350.

García Conde, A. y López Valcárcel, A., Episcopologio lucense, Lugo, Fundación Caixa Galicia, 1991.

González, T. (ed.), Censo de población de las provincias y partidos de la Corona de Castilla 
en el siglo XVI, Madrid, Imprenta Real, 1829, https://.jcyl.es/es/consultbibliotecadigitala/ registro.cmd?id=7823 (Consulta: 13-12-2018).

Historia Compostellana, cvra et stvdio Emma Falque Rey, Turnholti, Brepols, 1988.

Historia Compostelana. Introducción, traducción, notas e índices de Emma Falque, Madrid, Akal, 1994.

Hoyo, J. del, Memorias del Arzobispado de Santiago, edición preparada por Á. Rodríguez González y B. Varela Jácome, Santiago de Compostela, Porto y Cía. Editores, [1950?]. Itineraria et alia geographica, Turnholt, Brepols, 1965.

López Alsina, F., La ciudad de Santiago de Compostela en la Alta Edad Media, Santiago de Compostela, Ayuntamiento de Santiago de Compostela, 1988.

- "Da protoparroquia ou parroquia antiga altomedieval á parroquia clásica en Galicia", en García Pazos, F. (coord.), A parroquia en Galicia: presente, pasado e futuro, Santiago de Compostela, Xunta de Galicia, 2009, pp. 57-75.

- "El Parrochiale Suevum y su presencia en las cartas pontificias del siglo XII", en Herbers, K., Engel, F. y López Alsina, F. (eds.), Das begrenzte Papsttum: Spielräume päpstlichen Handelns, Legaten, delegierte Richter, Grenzen, Berlín, De Gruyter, 2013, pp. 105-133.

López Quiroga, J., “El I y II Concilios de Braga y el 'parroquial suevo': Élites eclesiásticas y control del territorio en la Gallaecia del siglo VI", en López Quiroga, J. (coord.), In tempore sueborum: el tiempo de los suevos en la Gallaecia (411-585), el primer reino medieval de occidente, Ourense, Deputación de Ourense, 2018, pp. 139-144.

López Sangil, J. L. y Vidán Torreira, M., "Tumbo viejo de Lugo (transcripción completa)", Estudios mindonienses, 27 (2011), pp. 11-373.

López, T., Mapa general del obispado de Lugo, Madrid, 1768, http://bibliotecadigital.rah.es/ dgbrah/es/consulta/registro.cmd?id=12890 (Consulta: 12-11-2018).

Loscertales de García de Valdeavellano, P., Tumbos del monasterio de Sobrado de los Monjes, Madrid, Archivo Histórico Nacional, 1976.

Mansilla Reoyo, D., Geografía Eclesiástica de España. Estudio histórico-geográfico de las diócesis, Roma, Iglesia Nacional Española, 1994.

Novo Güisán, J. M., "Lugo en los tiempos oscuros: las menciones literarias de la ciudad entre los siglos V y X", Boletín do Museo Provincial de Lugo, t. 8, vol. 2 (1997-1998), pp. 177-194.

Nomenclátor de Galicia, Xunta de Galicia, https://www.xunta.gal/nomenclator (Consulta: 14-11-2018).

Pardo de Guevara y Valdés, E., Los señores de Galicia. Tenentes y Condes de Lemos en la Edad Media, A Coruña, Fundación Pedro Barrié de la Maza, Instituto de Estudios Gallegos "Padre Sarmiento" CSIC, 2000.

Peiró Graner, N., El Señorío Episcopal lucense en el siglo XVI. Estructura y administración, Lugo, Servicio de Publicaciones Excma. Diputación Provincial de Lugo, 1998.

Portela Silva, E., La región del Obispado de Tuy en los siglos XII a XV, Santiago de Compostela, El Eco Franciscano, 1976.

- Documentos da Catedral de Lugo. Século XIV, Santiago de Compostela, Consello da Cultura Galega, 2007.

Quintana Prieto, A., El Obispado de Astorga en el siglo XII, Astorga, Publicaciones del Archivo Diocesano de Astorga, 1985.

Rodríguez Fernández, C., La colección diplomática de San Vicente del Pino, Tesis doctoral inédita, Granada, Facultad de Filosofía y Letras, 1990, http://cirp.es/codolga/files/san_ vicente_do_pino.pdf (Consulta: 07-05-2019).

Sánchez Pardo, J. C., "Organización eclesiástica y social en la Galicia tardoantigua. Una 
perspectiva geográfico-arqueológica del parroquial suevo'", Hispania Sacra, vol. LXVI, 134 (2014), pp. 439-480.

Tumbo viejo de la catedral de Lugo, Archivo Histórico Nacional, CODICES, L.1043, http:// pares.mcu.es/ (Consulta: 15-11-2018).

Vaquero Díaz, M. B. y Pérez Rodríguez, F. J., Colección documental del Archivo de la Catedral de Ourense, León, Centro de Estudios e Investigación "San Isidoro", Caja España de Inversiones, Archivo Histórico Diocesano, 2010.

Vázquez Bertomeu, M., A Igrexa de Santiago contra 1500: O Libro do Subsidio, Noia, Lóstrego, 2003.

Vilariño de Barbeito, R. R., Monforte, sus monumentos, leyendas y tradiciones, Monforte de Lemos, El Eco de Lemos, 1896. 